\title{
JOHN DEWEY E PAULO FREIRE: DUAS VISÕES DA EDUCAÇÃO
}

\section{JOHN DEWEY AND PAULO FREIRE: TWO VISIONS OF EDUCATION}

\author{
Augusto Kessai Agostinho Chicava \\ Universidade Federal do Rio Grande do Sul, Porto Alegre, RS, Brasil. E-mail: augustochicava@yahoo. \\ com.br \\ https://orcid.org/0000-0001-9879-1629
}

\begin{abstract}
Armindo Armando Nhanombe
Universidade Nova de Lisboa, Portugal. E-mail: mindosba@yahoo.com.br
\end{abstract}

DOI: https://doi.org/10.46550/amormundi.v1i1.9

Recebido em: 25.09.2020

Aceito em: 27.10.2020

\begin{abstract}
Resumo: O ensaio tenciona analisar duas visões de educação: democrática e libertadora em John dewey e Paulo Freire. Partimos do pressuposto que Dewey foi um intelectual interessado em difundir a educação democrática e progressiva, e Paulo Freire difundiu sua pedagogia libertadora a partir da conscientizaçāo. Propôs-se usar o método descritivo e analítico, a partir duma análise crítica e reflexiva das obras de Dewey, basicamente: Democracia e Educação, Como Pensamos e de Freire, Pedagogia de Oprimido e Pedagogia de Autonomia. Como resultado inferiu-se que Dewey assim como Freire são sempre atuais, e que nos tempos hodiernos a educação luta por ser democrática, libertadora e acima de tudo participativa. Dewey e Freire são incontronáves na educação, sobretudo quando se fala de metodologias, daí que sem sombra de dúvidas estáo na origem dos vários métodos e metodologias de processo de aprendizagem. Toda aprendizagem que tenha pretensa de ser democrática ou libertadora, não deve descurar da teoria e nem prática, mas conexação das duas.
\end{abstract}

Palavras-chave: Educação. Democracia. Liberdade. Conscientização

Abstract: The essay intends to analyze two views of education: democratic and liberating in John dewey and Paulo Freire. We start from the assumption that Dewey was an intellectual interested in spreading democratic and progressive education, and Paulo Freire spread his liberating pedagogy through awareness. It was proposed to use the descriptive and analytical method, from a critical and reflective analysis of Dewey's works, basically: Democracy and Education, As We Think and of Freire, Pedagogy of the Oppressed and Pedagogy of Autonomy. As a result, it was inferred that Dewey as well as Freire are always current, and that in modern times education strives to be democratic, liberating and above all participatory. Dewey and Freire are uncontrollable in education, especially when it comes to methodologies, hence they are undoubtedly at the origin of the various methods and methodologies of the learning process. Any learning that claims to be democratic or liberating, must not neglect theory and practice, but a connection between the two.

Keywords: Educação. Democracy. Freedom. Awareness. 


\section{Introduçáo}

presente ensaio procura analisar as relações da educação democrática e progressista de John Dewey e educação libertadora e conscientizadora de Paulo Freire respectivamente. Partindo do pressuposto que John Dewey foi um intelectual interessado em difundir a educação progressiva, e Paulo Freire difundiu sua pedagogia libertadora.

Enquanto Dewey tem o conceito da Experiência como fator central de seus pressupostos, chega à conclusão de que a escola não pode ser uma preparação para a vida, mas sim, a própria vida. Assim, para ele, vida, experiência e aprendizagem estão unidas, de tal modo que a função da escola se encontra em possibilitar uma reconstrução permanente feita pela criança, a partir de Experiência. Ressalta-se que para a compreensão das idéias de John Dewey (1859-1952), é necessário situar o seu pensamento no contexto do pragmatismo norte-americano, no qual ele está inserido ao lado de Charles Peirce e William James. O pensamento filosófico pedagógico de Dewey tem em vista uma educaçáo progressiva, uma escola democrática e uma escola laboratório. Tudo isto visto no contexto de uma filosofia que se pretende pragmática ou instrumentalista.

Paulo Freire partiu duma tendência progressista, na qual apresenta-nos uma concepção de educação que é libertadora e libertária. O projeto pedagógico democrático de Freire fazia frente à educação que forjava nos sujeitos a docilidade e opressão. Freire elaborou uma teoria baseada na pedagogia libertadora que é usada em alguns sistemas educativos do mundo. A pedagogia de Paulo Freire vincula a educaçáo à luta e a organizaçáo de classe. Ele idealizou uma educação que contemplava os indivíduos e as dinâmicas da vida social e económica. Paulo freire Propunha uma pedagogia específica, associando estudo, experiência vivida, trabalho, pedagogia e política.

Partindo do que foi exposto acima, pretende-se fazer um encontro entre Dewey e Freire, dois teóricos da educação que consideram uma das bases educativas o "saber ensinar a pensar", propondo a análise de duas categorias: a experiência e o pensar. Essas categorias são essenciais para a prática da liberdade. Freire extrai alguns trechos do pensamento do John Dewey para construir a sua pedagogia. A ideia de aprender fazendo, o trabalho cooperativo, a relaçáo entre a teoria e prática, o método de iniciar aula ou o trabalho educativo usando a linguagem dos alunos que Freire expõe são as características da pedagogia de Dewey.

Neste contexto pode-se afirmar que dialogar com estes autores torna-se fundamental para compreender a pedagogia contemporânea. Conduzindo a reflexáo nestes termos, pretendese contribuir para um ensino mais prático e empreendedor e, ao mesmo tempo, incentivar um ensino teórico prático.

\section{Educação democrática e progressiva em John Dewey}

A educação democrática e progressiva é uma democratização das relações pedagógicas e, não uma rejeição da autoridade, por isso, a escola deweyana é uma escola democrática. $\mathrm{O}$ princípio da aprendizagem está focalizado na experiência pessoal, sua filosofia da educaçáo bem elaborada dá margem à abrangência dos atores sociais que operam na experiência individual. Dewey diz que é preciso aprender-se com a própria vida.

Daí a sua preocupação com a tensa relação entre disciplina e liberdade, o que lhe levou a expor a problemática a partir da reflexão em torno do ordenamento lógico do pensamento. 
Dewey toma como ponto de partida duas concepçóes diferentes: uma que considera essencial a disciplina e outra que tem liberdade na organizaçáo dos processos formativos. O autor entende que cada uma delas tem noção errada do que significa o princípio que professa. Disse Dewey (1959);

A disciplina pode ser identificada: aos atos mecânicos que têm por fim embutir com repetidas pancadas, uma substância estranha num material resistente, ou comparável à rotina maquinal com que se emprestam a bisonhos recrutas o porte e os hábitos marciais que lhes eram, como de esperar, totalmente alheios (p. 92).

Para Dewey esta reflexão aponta para a direção contrária à disciplina mental, pois o objetivo, nesse caso, não é desenvolver o hábito de pensar, mas atingir maneiras de agir uniforme. Para Dewey a disciplina é positiva e construtivista. Disto se depreende que Dewey desafia a disciplina a sair de si mesma e a concretizar-se num outro, diferente de si, a concretizar-se numa ação não só mental, mas também pragmática. Portanto, ele fala de uma abertura pragmática que implica uma conjugação multiforme dos saberes.

$\mathrm{Na}$ perspectiva da formação da liberdade intelectual, Dewey desenvolve uma reflexão atualizada sobre interesse e disciplina, ao discutir a tese de que disciplinado é o indivíduo que se forma aprendendo a exercitar a reflexão sobre as suas açôes e empreendê-las de maneira que haja resultado.

Disciplina significa a energia à nossa disposição; o domínio dos recursos disponíveis para levar em diante a atividade empreendida. Saber o que se deve fazer e fazê-lo prontamente e com a utilidade dos meios requeridos, significa ser disciplinado, quer se trate de um exército, quer de um espírito. A disciplina é positiva. Humilhar o espírito, domar as propensões, compelir á obediência, mortificar a carne, fazer um subalterno executar um trabalho desagradável - estas coisas são ou não disciplinadoras, na medida em que desenvolverem a compreensão daquilo que se tenha em vista, e em deem perseverança para a ação (DEWEY, 1979, p. 141).

Dewey fala da necessidade de evitar os preconceitos, a arrogância do saber tido certo, é preciso ter o "espírito aberto". Esta ideia pode ser definida como independência de preconceitos, de partidarismo e de outros hábitos como o de cerrar a mente e indispô-la à consideração de novos problemas e novas ideias.

A indolência mental concorre grandemente para que se entaipe o espírito contra ideias novas. O caminho da mínima resistência e mínimo esforço é sulco mental já traçado. E bem penosa labuta é de alterar velhas crenças. A presunção tem, frequentemente, por sinal de fraqueza o admitir que uma crença que uma vez adotamos esteja errada. [...] Medos inconscientes também nos arrastam a atitudes puramente defensivas, que funcionam como cota d'armas, não apenas para barrar novas concepçóes, mas para impedir a nós próprios o acesso a nova observaçáo. $\mathrm{O}$ efeito cumulativo dessas forças é o de enclausurar o espírito e promover o afastamento de novos contactos intelectuais, necessários à aprendizagem (DEWEY, 1979, p. 39).

Portanto para Dewey, só haverá uma verdadeira aprendizagem, se houver uma metodologia que estimule o aluno. O pensamento deve ser liberal, ou por outra, deve ser uma escola democrática que ajuda o aluno no desenvolvimento da capacidade de raciocínio e espírito crítico. Nisto, o professor deve ser um mero tutor, um facilitador na aprendizagem, devendo possibilitar escolhas e soluçóes criativas. É preciso problematizar o ensino, que leve o aluno a 
uma aprendizagem significativa, pois o mesmo utiliza diferentes processos mentais e desenvolve a capacidade de assumir a responsabilidade pela sua formaçáo.

A educação não se deveria restringir ao ensino do conhecimento como algo acabado, mas o saber e a habilidade adquiridos pelo aluno deveriam poder ser integrados à sua vida como pessoa, cidadão e ser humano. Devia ser uma educação progressiva, mais pragmática, concreta que o projeta ao empreendedorismo e ao mercado de emprego.

A escola democrática faz com o aluno seja protagonista do seu saber, isto é, o aluno aprender a aprender. O princípio é que os alunos aprendem melhor realizando tarefas associadas aos conteúdos ensinados. $\mathrm{O}$ aluno é o fazedor do seu próprio processo de aprendizagem. É este o aspecto pelo qual o método cativa algumas instituiçôes do ensino, disseminando-se em muitas instituiçóes de educação.

A iniciativa e a independência levam à autonomia que na realidade são virtudes de uma sociedade realmente democrática, ao contrário do ensino tradicional que valoriza a obediência. Mas para que isso se torne realidade nas escolas, é necessário repensar os métodos educacionais utilizados pelos professores na sala de aula aquando da sua formação.

Foi por isso que Dewey investigou a experiência em seu aspecto essencialmente dinâmico, e toda a experiência modificada ocorre pelo meio, concepção que leva o autor a admitir a existência de processo contínuo de criação de conexôes e continuidades, propiciando permanentes recriaçóes dos elementos envolvidos.

Defensor da Escola Ativa, Dewey apontou a importância da aprendizagem partindo da experiência. Da crítica à escola tradicional, instauradora de comportamentos de submissão e obediência, o autor propôs uma inversão de valores que considerasse iniciativa, originalidade e cooperação, possibilitando a libertação das potencialidades críticas do indivíduo, objectivando náo a mudança social, mas o aperfeiçoamento.

Dewey desenvolveu teorias pedagógicas progressistas, particularmente em relação à inserção do estudante, sujeito no processo de aprendizagem. Assim tornou a discussão sobre a democracia na organização social e a defesa da escola pública muito fundamental na pedagogia progressista.

Pode-se inferir este método de Dewey, instrumentalismo, com as suas próprias palavras:

O que leva o homem ao conhecimento não é um fim em si mesmo, mas a necessidade de apropriaçáo da realidade. $\mathrm{O}$ pensamento não é, em última instância, saber, mas apropriaçáo instrumental para ter domínio sobre as coisas. O meio impóe dificuldades, mas o pensamento humano serve de instrumento à sua adaptação (DEWEY, 1980 p. 128).

Sendo que na verdade, a busca do pensamento, é o que leva o homem a superar problemas, bases que faz Dewey produzir ampla reflexão política, particularmente em relação aos fundamentos filosóficos, que justificam a valorização da experiência educativa e sobretudo a ligação quase intrínseca entre a vida, a experiência e a aprendizagem. Esta escola democrática e progressista fez com que Dewey pensasse em algo que pode chamar-se de Escola laboratório, que seria o lugar onde se pode praticar o que se aprendeu, ou se quisermos na linguagem de Dewey, é o lugar onde o aluno aprende a aprender. 
3 Escola como laboratório: o lugar da testagem dos métodos pedagógicos

Influenciado pelo empirismo, Dewey criou uma escola laboratório ligada à universidade onde lecionava para testar métodos pedagógicos. Ele insistia na necessidade de estreitar a relação entre teoria e prática, pois acreditava que as hipóteses teóricas só têm sentido no dia- a- dia. O princípio é que os alunos aprendem melhor realizando tarefas associadas aos conteúdos ensinados. Nesta escola, as atividades manuais e criativas ganharam destaque no currículo e as crianças passaram a ser estimulados a experimentar e pensar por si mesmas.

A escola laboratório ou lab school fundada na universidade de Chicago em 1896 era como um laboratório, comparável a quaisquer outros laboratórios científicos, onde poderiam ser desenvolvidas experiências para a constituição, elaboração e desenvolvimento de temas e atividades práticas, tendo em consideração as necessidades e aptidóes das crianças em função do seu estágio de desenvolvimento, as suas capacidades e experiências. A escola laboratório permitia também o estudo da mente das crianças e do seu desenvolvimento.

Dewey apoia as atividades manuais, uma vez que estas apresentam situaçóes concretas para serem resolvidas. E além do mais desenvolve o espírito de trabalho em equipa, pois através da divisão de tarefas entre os estudantes, se estimula a cooperação e consequentemente se desenvolve o espírito social (DEWEY, 1980, p. 27). Na filosofia de Dewey o estudante é o fazedor do seu próprio processo de aprendizagem. Mas quando falamos de escola laboratório, náo significa que a educação nova de Dewey não dá importância às matérias de estudo. Pelo contrário, este ensina a não fazer uma dicotomia entre a teoria e a prática.

É muito importante referir que tudo isso passa pelo raciocínio analítico, pois, Dewey considera o raciocínio como uma série de passos que seguem numa sequência ordenada, onde: 1) Problema: a pessoa motivada encontra obstáculo; 2) diagnóstico: ela localiza a fonte do problema e considera sua estrutura. Esta é a esfera da capacidade analítica para abstrair e formar conceitos; 3) hipótese: ela formula uma ou mais conjunturas. Esta é a esfera da imaginação criativa; 4) dedução: a pessoa apresentada tenta elaborar uma conclusão possível de sua hipótese, que será verdadeira se e somente se a hipótese for verdadeira. Esta é a esfera da lógica e da experiência, (MARTIN; SPERLING, 2003, p. 63).

Assim Dewey, concebe o raciocínio analítico como capacidade de raciocinar rapidamente através da percepção. E, que a origem da ciência está nos problemas que estão associados à explicação de comportamento de alguns aspectos do mundo, onde as hipóteses são criticadas e comprovadas. Fala duma escola democrática em que o estudante é o protagonista do seu saber, isto é, o estudante deve aprender a aprender, pois o conhecimento só é possível partindo da experiência.

\section{A pedagogia do oprimido, como humanista e libertária em Paulo Freire}

Antes de mais nada importa referir, que a vocação de educar de Paulo Freire nasceu, cresceu e se desenvolveu nas suas diversas experiências no nordeste do Brasil, onde grande parte da população vivia em situação de analfabetismo e em extrema situação de pobreza. Essa realidade de analfabetismo e pobreza coloca o homem numa condição de objeto, de coisa, de ser menos. Dentro desta realidade, ele perdia sua consciência, vivia no anonimato da massificação e da alienação. Mas deixemos que seja ele a falar: 
A pedagogia do oprimido, que busca a restauração da intersubjetividade, se apresenta como pedagogia do homem. Somente ela, que se anima de generosidade autêntica, humanista e não 'humanitarista', pode alcançar este objectivo. Pelo contrário, a pedagogia que, partindo dos interesses egoístas dos opressores, egoísmo camuflado de falsa generosidade, faz dos oprimidos objetos de seu humanismo, mantém e encarna a própria opressão. É instrumento de desumanização (FREIRE, 2014, p. 56).

Freire introduz a sua pedagogia de oprimido. Esta pedagogia fornece-nos instrumentos indispensáveis pra a didática da libertação do oprimido e do opressor. E a grande justificativa da Pedagogia do oprimido é a desilusão filosófica e política sobre a relação dominação - opressora e ou oprimido, propondo a superação desta contradição a partir de uma re-humanização dos oprimidos, através da prática pedagógica, auxiliando a libertaçáo. A opressão e as suas causas devem ser reflectidas, resultando em lutas orientadas pela pedagogia, enfrentando o medo da liberdade. Este não se liberta sozinho, mas em comunhão com outras de situaçôes semelhante, dialogando, colocando-se como sujeito e não objecto. Nada justifica a manipulação. Esta deve ser liderada pelo oprimido.

Freire, na sua longa caminhada em busca da educação libertadora, se empenha nos seus trabalhos em expressar o seu sentimento de transformação da realidade opressora em realidade igualitária, sua luta é a favor dos menos favorecidos, os marginalizados da sociedade. "A educaçáo tradicional consente que os excluídos e marginalizados da sociedade permaneçam no estado de consciência ingênua e alienação. No contexto capitalista, a educação é moldada a atender os interesses do capital, deste modo os oprimidos náo compreendem a realidade que vivem" (FREIRE, 2005, p. 43).

De acordo com Freire, o dominador faz do dominado instrumento de manobra, o sujeito é educado para não desenvolver a consciência crítica, é negado o direito do homem de se humanizar e o direito do pensar autêntico. Freire coloca a humanização como algo que é vocação de todos os homens e a desumanização, que está presente na realidade opressora, como uma distorção histórica. Entretanto a realidade opressora apresenta o direito de ser mais como vocação dos dominadores e o ser menos como a vocação dos dominados.

Freire busca como ideal a conscientização para o conhecimento da realidade e das relaçóes de poder existente na sociedade, isto para que o indivíduo possa transformar, modificar o que lhe é oferecido como se fosse o máximo que poderíamos ter e muitas vezes ver o dominador como um sujeito generoso, porque sua ideologia já corrompeu e alienou o cidadão.

A sua prática pedagógica fundamenta-se principalmente na crença de que o educando assimila o objecto de estudo fazendo uso de uma prática dialéctica com a realidade, em contraposição à educação bancária, tecnicista e alienante. Para Freire, no momento em que o saber torna-se um produto cuja fabricação é assegurada por uma instituição oficial chamada escola, essa escola torna-se em corpo separado da sociedade, o conteúdo do ensino não tem nada a ver com o aluno nem com a realidade concreta e imediata como quem aprende.

Freire advoga que o educando deve criar a sua própria educação, fazendo o seu próprio caminho, e não seguindo um já previamente construído, libertando-se dos esquemas alienantes e, o educador deve seguir o rumo do seu aprendiz apenas como facilitador deste na construção do seu próprio conhecimento ou na conquista da sua liberdade. Assim ele diz:

$\mathrm{Na}$ realidade, na medida em que esta modalidade educativa se reduz a um 
conjunto de métodos e de técnicas com as quais educandos e educadores observam a realidade social (quando a observam), simplesmente para descrever, esta educação é tâo domesticada como qualquer outra. A educação para libertação náo pode ser a que procura libertar os educandos das pirraças para lhes oferecer projetores. Pelo contrário, é a que se propóe, como praxis social, contribuir para libertar os seres humanos da opressão que se encontram na realidade objectiva. Por isto mesmo, é uma educação, tão política como aquela que, servindo as elites do poder, se proclama apesar de tudo neutra. Daí que esta educação não possa ser posta em prática, em termos sistemáticos, antes da transformação radical da sociedade (FREIRE, 1977, p. 118).

O que se pode observar nesta citação é que Freire também nega as práticas que se dizem ser educativas a partir das quais somente é necessário observar e descrever a realidade, é necessário uma postura frente esta realidade, uma subjetividade que seja coesa e que tenha argumentos, por isso, Freire a afirmava que a educação é um ato político.

Para Freire toda a tarefa de educar só é autenticamente humanista na medida em que faz perder o medo da liberdade e na medida em que pode criar no educando um processo de recriação, de busca, de independência e de solidariedade. Deve facultar ainda, uma comunicação entre sujeitos que atuam sobre o mundo transformando-o, se é que se quer chegar ao homem como ser concreto inserido numa determinada realidade histórica. Mas Freire explica a sua perspectiva:

Não posso ser professor se não percebo cada vez melhor que, por não poder ser neutra, minha prática exige de mim uma definiçẫo. Uma tomada de posição. Decisão. Ruptura. Exige de mim que escolha entre isto ou aquilo. Não posso ser professor a favor de quem quer que seja e a favor de não importa o quê. Não posso ser professor a favor simplesmente do Homem ou da Humanidade, frase de uma vaguidade demasiado contrastante com a concretude da prática educativa. Sou professor a favor da decência contra o despudor, a favor da liberdade contra o autoritarismo, da autoridade contra a licenciosidade, da democracia contra a ditadura de direita ou de esquerda (FREIRE, 2014, p. 100).

Dentro da perspectiva de Freire há um posicionamento sociológico e antropológico da condição do homem participante de um meio e dos pressupostos que envolvem a educaçáo, ou seja, analisa a problemática dos processos de ensino aprendizagem através do jogo de interesses políticos, econômicos, sociais e culturais, em suma através de nossa realidade. Por isso, que suas obras são uma denúncia aos modos que constituem a educação oferecida aos homens das camadas populares.

Deste modo, ele afirma que:

A pedagogia do oprimido, como pedagogia humanista e libertadora, terá dois momentos distintos. $\mathrm{O}$ primeiro que os oprimidos vão desvelando o mundo da opressão e vão comprometendo-se, na praxis, com sua transformação; o segundo, em que transformada a realidade opressora, esta pedagogia deixa de ser do oprimido e passa a ser pedagogia dos homens em processo de permanente libertaçẫo (FREIRE, 2014, p. 57).

Freire (2014) expóe que está disseminada na sociedade a questão do perigo da conscientização crítica que conduz a uma pedagogia libertadora, um dos argumentos é que a conscientização conduz à anarquia. Entretanto, esta afirmação é pertencente ao senso comum elaborada pelos dominantes como forma de se defender dos movimentos e pedagogias progressistas, estes grupos elencam como necessidade primeira o desenvolvimento de um processo 
de conscientização. Mas Freire faz uma ressalva sobre o modo como se dá a conscientização:

Não há conhecimento se da sua prática não surge a ação consciente dos oprimidos, enquanto classe social explorada, na luta pela sua libertação. Por outro lado, ninguém conscientiza ninguém. O educador e o povo conscientizam- se através do movimento dialéctico entre a reflexão crítica sobre a ação interior e a ação subsequente no processo daquela luta" (FREIRE, 1977, p. 118).

Freire (1984) define a conscientização como sendo uma extensão da tomada de consciência. Há três tipos de consciência (consciência mágica; consciência ingênua e consciência crítica) na sociedade com características antagónicas resultantes das estruturas sociais também contrárias.

\section{Aproximaçóes de duas visóes da educação: Dewey e Freire}

Os dois autores apresentam vários pontos que convergem no que diz respeito a educação, mas em particular, sobre a aprendizagem. O que é visível é que ambos negam o modelo tradicional de educação.

Enquanto Dewey apresenta educação tradicional como memorização, Freire denomina pedagogia bancária. A crítica que faz a educação tradicional é devido ao seu carácter seletivo, discriminatório, ineficaz. A escola tradicional oculta as responsabilidades, se coloca na posição de vítima frente aos problemas e transfere a culpa aos alunos, que se caracterizam nesta prática como ineficazes, inoperantes, ignorantes, passivos.

$\mathrm{Na}$ defesa por uma educação de qualidade, percebemos que ambos elaboram suas teorias na ação, na conscientizaçáo, enfim num método que conduza o educando à autonomia, criatividade, curiosidade e a inventabilidade. Defendem que uma nova educação faz-se necessária para que as mudanças sociais ocorram. Para Dewey estes alicerces fundam-se numa escola Nova ou Progressista, onde o mais importante na aprendizagem dos alunos é a relação que estes devem ter uns para com os outros e o ensino é individualizado, é ativo, onde se estimula a criatividade do aluno e do professor, quer dizer, o aluno deve possuir um espírito crítico na sua aprendizagem, tomando, neste caso, uma iniciativa pessoal. Já para Freire estes alicerces são encontrados na própria sociedade, na conscientização, na investigaçáo de temas geradores, no diálogo entre iguais.

Dewey e Freire advogam, também uma boa formação de professores, formação esta, crítica e dialógica. Com educadores conscientes e conhecedores profundos das relaçóes e realidades sociais, poderemos construir novas relaçóes, que possibilitarão aos educandos desvendar o mundo do conhecimento, o mundo da informação, o mundo político, o mundo da cultura, o mundo social e orientar para que o educando se descubra como histórico e produtor de cada um destes mundos.

Paulo Freire é um pensador comprometido com a vida: não pensa ideias, apenas, mas também pensa a existência e, aflora o seu pensamento numa pedagogia em que o esforço totalizador da prática humana busca retotalizar-se na interioridade desta como prática da liberdade.

$\mathrm{Na}$ Pedagogia do oprimido no seu segundo parágrafo da introdução diz o seguinte: "um dos aspectos que surpreendemos, quer que os cursos de capacitação que damos e em que analisamos o papel da conscientização, quer na aplicação de uma educação realmente libertadora, 
é o medo da liberdade" (FREIRE, 2014, p. 31). Não é possível tratar da educação libertadora, sem pensar que a pedagogia também precisa de ser libertadora. Como Freire definia:

[...] aquela que tem que ser forjada com ele e não para ele, enquanto homens e povos, na luta incessante de recuperação de sua humanidade. Pedagogia que faça da opressão e de suas causas objecto de reflexão dos oprimidos, de que resultará o seu engajamento necessário na luta por libertação, em que esta pedagogia se fará e refará. o grande problema está em como poderão os oprimidos, que hospedam o opressor em si, participar da elaboração, como seres duplos, inautênticos, da pedagogia de sua libertação (FREIRE, 2014, p. 43).

Paulo enfatiza a necessidade de se ter a consciência da liberdade além de salientar o que ele denomina pedagogia do oprimido onde a educação existe como uma prática de dominação e a pedagogia do oprimido que precisa ser realizada para que surja uma educação como prática da liberdade. Para Freire, não basta somente que o oprimido tenha consciência da opressão, além disso, ele deve ter a consciência de que precisa transformar a realidade. Logo, a educação para com o oprimido é um trabalho de conscientização.

A forma do opressor surgiu pela afirmação do homem enquanto individuo possuidor de direitos, tanto de luta pela liberdade trabalhista quanto pela desumanização que dá margem ao surgimento da luta pelo direito de cada ser humano. Sendo assim, dentro do sistema capitalista sempre haverá o que se sobrepóe mais ao sistema do que o outro, ainda mais se tratando do capital. Assim, até a educação virou um grande comércio.

Em relação a definição de oprimidos e opressores pode haver algumas contradiçóes; o que torna os opressores desumanizados é sua violência, e essa violência faz com que os oprimidos tendam a reagir lutando contra quem os oprime, contra quem os fez menos. Essa luta só adquire sentido quando o ser menos, ao buscar sua humanização, não se reconhece opressor devolvendo a quem o oprimiu tal violência. A libertação se dá á medida que o oprimido reconquista sua humanidade em ambos papéis que possivelmente ocupa, do ser mais e do ser menos. Assim sendo, pode correr-se o risco da "inversão dos papéis", ou seja, o oprimido pode passar a oprimir o opressor:

[...] é que, quase sempre, num primeiro momento deste descobrimento, os oprimidos, em vez de buscar a libertação na luta e por ela, tendem a ser opressores também, ou sub-opressores. A estrutura de seu pensar se encontra condicionada pela contradição vivida na situação concreta, existencial, em que se "formam". O seu ideal é, realmente, ser homens, mas, para eles, ser homens, na contradição em que sempre estiveram e cuja superação não lhes está clara, é ser opressores. Estes são o seu testemunho de humanidade (FREIRE, 2014, p. 44).

Freire em sua longa caminhada em busca da educação problematizadora e libertadora empenha-se nos seus trabalhos em expressar o seu sentimento de transformação da realidade opressora em realidade igualitária, sua luta é a favor dos menos favorecidos, os marginalizados da sociedade. A educação tradicional consente que os excluídos/marginalizados da sociedade permaneçam no estado de consciência ingênua e alienação. No contexto capitalista, a educaçáo é moldada a atender os interesses do capital, deste modo os oprimidos não compreendem a realidade que vivem.

O dominador faz do dominado massa de manobra, o sujeito é educado para não desenvolver a consciência crítica, é negado o direito do homem de se humanizar e o direito do pensar autêntico como menciona Freire (2005). Freire coloca a Humanização como algo que é 
vocação de todos os homens e a desumanização, que está presente na realidade opressora, como uma distorção histórica. Entretanto a realidade opressora apresenta o direito do ser mais como vocação dos dominadores e do ser menos como a vocação dos dominados.

Freire busca como ideal a conscientização para o conhecimento da realidade e das relaçôes de poder existente na sociedade, isto para que o indivíduo possa transformar, modificar o que lhe é oferecido como se fosse o máximo que poderíamos ter e muitas vezes ver o dominador como um sujeito generoso, porque sua ideologia já corrompeu e alienou o cidadão. Nesta realidade o termo cidadão não está presente ou é camuflado como se estivesse, tudo é falso, há uma pseudoparticipação, pseudoconsientização, pois o que há é uma cultura do silêncio, desumanização e exploração do homem pensante, que é colocado como coisa, como domesticado.

Para este pedagogo, o conhecimento é algo a ser construídos na coletividade, pelo qual o movimento da ação - reflexão é tido como fundamental. Sua pedagogia se caracteriza por ser dialógica e também dialética, Dialógica porque é através da comunicação que estabelecemos relaçóes com o outro, que edificamos a dialética em nossa vida e dialética porque não podemos dicotomizar os fundamentos da educação que são: ação - reflexão, subjetivo - objetivo, homem - mundo, educador - educando; nestas relaçôes não há o que é mais importante e o menos importante, não há a hierarquia de um sobre o outro. Nestes parâmetros a educação não é via de mão única, mas via de mão dupla, não é assimétrica, mas é simétrica (FREIRE, 2005).

Nosso pensamento caminha também nesta vertente de Freire e percebemos que quando o indivíduo entende o que foi mencionado, um grande e vasto caminho se abre e passa a entender muitos fatos ou condiçóes que nunca compreendera.

$\mathrm{Na}$ visão de Freire, para que haja equilíbrio na sociedade não é necessário que os papéis sejam trocados, ou seja, que opressores se tornem oprimidos e oprimidos se tornem opressores, se isto ocorresse teríamos um grande equívoco e uma grande contradição. Sua luta é para equalizar com qualidade e quantidade. Defende uma Pedagogia que liberte os marginalizados de sua condição de explorado e alienado, que estes possam se comunicar, agir e pensar.

Enquanto para Dewey a Educação tem como finalidade propiciar à criança condiçóes para que resolva por si própria os seus problemas, e não os tradicionais ideais de formar a criança de acordo com modelos prévios, ou mesmo orientá-la para um porvir. Assim, tomando o conceito de experiência como fator central de seus pressupostos, chega-se à conclusão de que a escola não pode ser uma preparação para a vida, mas sim a própria vida.

Para Dewey, o ensino e a aprendizagem baseiam-se numa compreensão de que o saber é constituído por conhecimentos e vivências que se entrelaçam de forma dinâmica, distante da previsibilidade das ideias anteriores. Deste modo, os alunos e professor detentores de experiências próprias, são aproveitados no processo. O professor, neste caso, tem uma visão sintética que é mais abrangente e clara acerca dos conteúdos, e os alunos uma visão sincrética que é confusa e náo muito clara daquilo que aprende, o que torna a experiência um ponto central na formaçáo de conhecimentos, mais do que os conteúdos formais. De acordo com estes factos, isto levará a uma aprendizagem essencialmente coletiva, assim como é coletiva a produção de conhecimentos.

Com estes aspectos e postos em prática, o processo de ensino e aprendizagem irá avante e, portanto, os alunos e o professor se enriquecerão e haverá, neste caso, a interação escolar de poder aprender e também de poder ensinar, mas tudo isto centrado no professor como orientador deste 
processo de ensino e aprendizagem.

\section{Consideraçóes finais}

O percurso histórico-filosófico das duas visôes de educação em Dewey e Freire permitiunos perceber que sempre foi preocupação do processo de aprendizagem ou ensino encontrar uma metodologia que respondesse às lacunas que se verificam nos formandos, que em muitos casos terminam mais teóricos que práticos. John Dewey vinca a necessidade de haver um ensino pragmático, uma escola democrática, em que o estudante deve aprender a aprender. Paulo Freire propunha uma pedagogia específica, associando estudo, experiência vivida, trabalho, pedagogia e política. Fizemos uma aproximação dos dois autores e vimos que os dois além de serem atuais, ambos convergem pelo fato de negarem a educação tradicional que não passa de memorização e repetição.

Os dois advogam uma educação participativa e democrática. $\mathrm{O}$ aluno deve ser o fazedor da sua própria aprendizagem. Ele aprende aprendendo. O professor aparece como um mero facilitador. E se quisermos podemos dizer que aula não se da mas faz-seccomplementam-se.

Tanto Dewey como Freire preocupam-se em apresentar o método que deve ser usado neste processo aprendizagem. Para Dewey tal método é o instrumentalismo que se baseia essencialmente na experiência. Aliás, para Dewey a vida, experiência e aprendizagem estão unidas, de tal forma que a função da escola se encontra em possibilitar uma reconstrução permanente feita pela criança, apartir da experiência.

A escola não pode ser preparação para a vida, mas sim, a própria vida. Enquanto que para Freire o seu método é a conscientização que deve ser feito através do diálogo. Esta conscientização leva-nos a transformar a nossa vida, a não cair na pedagogia do dominante, mas numa pedagogia libertadora. Para Freire o que o oprimido precisa é libertar-se. Deve haver uma acção política em favor da resolução dops problemas.

Por fim, podemos afirmar que Dewey e Freire são sempre atuais. E podemos afirmar que hoje a educação luta por ser democrática, libertadora e acima de tudo participativa. Dewey e Freire são incontronáveis na educação, sobretudo quando se fala de metodologias, daí que sem sombra de dúvidas estáo na origem dos vários métodos e metodologias de processo de aprendizagem.

Podemos concluir dizendo hoje quer-se métodos que seja teóricos-práticos e críticos. Quer-se um ensino que seja democrático e libertador. Isto é, que não descure nem a teoria e nem prática, mas que faz a conexação das duas.

\section{Referências}

DEWEY, John. Democracia e educaçáo. São Paulo: Trad. Godofredo Rangel e Anísio Teixeira, 4a ed. Campanha Editora Nacional, 1979.

DEWEY, John. Vida e educaçáo. $7^{a}$ ed. São Paulo: Melhoramentos, 1971.

DEWEY, John. Como pensamos. São Paulo: Trad. Haydee de Carmargo Campos. $4^{a}$ Ed. Companhia Editorial Nacional, , 1979. 
DEWEY, John. Experiência e natureza; Lógica: a teoria da investigaçáo; A arte como experiência; Vida e educaçáo; Teoria da vida moral. Sáo Paulo: Trad. de Murilo Leme, Anísio Teixeira, Leonidas de Carvalho, Abril Cultural, 1980.

MARTIN, M; SPERLING, A. Introdução à psicologia. São Paulo: Pioneira psicologia, 2003.

FREIRE, Paulo. Pedagogia do oprimido. Rio de Janeiro: Paz e Terra 57ª ed. 2014

FREIRE, Paulo. Pedagogia da indignação: cartas pedagógicas e outros escritos. Rio de Janeiro: Paz e Terra, 2014.

FREIRE, Paulo. Educaçáo como prática da liberdade. Rio de Janeiro: Paz e Terra, 1977.

FREIRE, Paulo. Educaçáo como prática da liberdade. Rio de Janeiro: 15 ed. Paz e Terra, 1984.

FREIRE, Paulo. Pedagogia da autonomia: Saberes necessários. São Paulo: 34 ed. Paz e Terra, 2006. 